\title{
POOPERACINIO SKAUSMO VALDYMO INTRAVENINIAIS LORNOKSIKAMU IR ACETAMINOFENU PALYGINIMAS PO RADIKALIŲ PROSTATEKTOMIJŲ
}

\author{
Ugnė Lindžiūtè ${ }^{1}$, Eglè Zlatkutè ${ }^{1}$, Tadas Urbonas ${ }^{1}$, Tomas Bukauskas ${ }^{2}$, \\ Donatas Simonaitis ${ }^{2}$, Andrius Macas ${ }^{2}$ \\ ${ }^{1}$ Lietuvos sveikatos moksly universiteto Medicinos akademija, \\ ${ }^{2}$ Lietuvos sveikatos moksly universiteto Medicinos akademijos Anesteziologijos klinika
}

Raktažodžiai: pooperacinis skausmas, nesteroidiniai vaistai nuo uždegimo, intraveninis lornoksikamas, intraveninis acetaminofenas.

\section{Santrauka}

Nesteroidiniai vaistai nuo uždegimo yra skirti įvairaus tipo ir lokalizacijos skausmui malšinti. Gera pooperacinio skausmo kontrolè yra svarbi norint išvengti skausmo potencijuojamo paciento būklès pablogejjimo, pvz., tachikardijos, hipertenzijos, miokardo išemijos, alveoliu ventiliacijos sumažèjimo, prasto žaizdų gijimo. Šiame tyrime lyginsime acetaminofeno ir lornoksikamo efektyvumą pooperaciniam skausmui malšinti.

Darbo tikslas: ịvertinti lornoksikamo analgezijos efektyvumo jëgą pooperaciniu laikotarpiu pacientams po radikaliu prostatektomijų.

Metodai. Itraukti 35 pacientai, gydyti 2015-2016 metais LSMUL KK Urologijos skyriuje, kuriems atlikta radikali prostatektomija. Gavus raštišką sutikimą, atsitiktiniu būdu pacientams operacijos pabaigoje sušvirkščiami intraveninio lornoksikamo $8 \mathrm{mg}$ arba acetaminofeno $1000 \mathrm{mg}$. Pilvo skausmas vertinamas prieš operaciją, po operacijos praejus 3,6 , 12 ir 24 valandoms.

Rezultatai. Prieš operaciją pilvo skausmą lornoksikamo (L) grupejje jaute 1 (6,25 proc.) pacientas, o acetaminofeno (A) grupejje 1 (5,26 proc.) pacientas jautè rankos skausmą. Po operacijos praejjus 3 valandoms A grupèje 9 (47,37 proc.) pacientai skundèsi vidutinio stiprumo skausmu ir 3 (15,79 proc.) - stipriu skausmu. L grupeje po operacijos praejus 3 valandoms 3 (18,75 proc.) pacientai jaute stiprų skausmą. Tarp A ir L vaistų po operacijos praejjus 3, 6, 12 ir 24 val. statistiškai reikšmingo skirtumo nebuvo ( $\mathrm{p}=0,329 ; \mathrm{p}=0,917 ; \mathrm{p}=0,4 ; \mathrm{p}=0,903$, atitinkamai).
Išvados. Intraveninis lornoksikamas ir acetaminofenas efektyviai malšina skausmą po radikalių prostatektomijų. Lornoksikamas i/v nuo skausmo toks pat efektyvus kaip paracetamolis i/v pacientams po radikalių prostatektomijų. Intraveninis lornoksikamas ir paracetamolis yra tinkami vartoti vidutinio stiprumo ir stipriam skausmui malšinti ankstyvuoju pooperaciniu laikotarpiu.

\section{Ivadas}

Nesteroidiniai vaistai nuo uždegimo (NVNU) yra skirti įvairaus tipo ir lokalizacijos skausmui malšinti. Šios grupés vaistai klasifikuojami pagal selektyvumą ciklooksigenazei-1 ir 2 (COX-1, COX-2). NVNU slopindami COX1, COX-2 ir 5-lipooksigenazę, slopina laisvujų radikalų susidarymą ir prostaglandinų sintezę, taip sumažindami skausmą, uždegimą ir padidejjusią kūno temperatūrą. Lornoksikamas, kuris priklauso NVNU oksikamų pogrupiui, neselektyviai slopina ciklooksigenazès-1 ir 2 veikimą (1). Dèl minètų poveikių NVNU yra vieni dažniausiai vartojamų nereceptinių vaistų. NVNU efektyviausiai malšina silpną ir vidutinio stiprumo skausmą (2). Acetaminofenas priklauso analgetiku grupei, kurie neselektyviai slopina COX-1 ir COX-2 (3), tačiau neturi uždegimą slopinančio poveikio. Perioperaciniu periodu svarbu užtikrinti kuo geresnę skausmo kontrolę, nes skausmas išsekina ligoni, sulètina sveikimą po operacijos, neigiamai veikia paciento psichiką ir tolimesni darbingumą ir taip blogina gyvenimo kokybę (4). Optimalus pooperacinio skausmo valdymas yra svarbus norint išvengti skausmo potencijuojamo paciento būklès pablogejimo, pvz., tachikardijos, hipertenzijos, miokardo išemijos, alveolių ventiliacijos sumažẻjimo, prasto žaizdų gijimo (5).

Tiek acetaminofenas, tiek lornoksikamas yra vartojami lètiniam bei ūmiam skausmui malšinti. Mentes ir bendraautoriai (6) lygino $8 \mathrm{mg}$ lornoksikamo i/v su $1 \mathrm{mg} / \mathrm{kg}$ tra- 
madolio i/v analgeziją po kirkšnies išvaržuc operacijų. Rezultatai parodé, kad abu vaistai sukèlè efektyvią ir greitą analgeziją [6], bet nebuvo lyginta su placebo. Tuo tarpu kitame tyrime (7) buvo lyginti lornoksikamas $(4,8,16,20 \mathrm{mg}) \mathrm{i} / \mathrm{m}$, morfinas $(10,20$ $\mathrm{mg}$ ) $\mathrm{i} / \mathrm{m}$ ir placebo grupé po dantų operacijų. Abu vaistai buvo efektyvesni už placebo ir skausmą malšino 4-6 valandas. Arslan ir bendraautoriai (8) vertino pooperacini skausmą po tiroidektomijų. Vienoje grupejje buvo vartota $\mathrm{i} / \mathrm{v} 8 \mathrm{mg}$ lornoksikamo operacijos pabaigoje bei dvi dozès po $8 \mathrm{mg}$ i/v kas 12 valandų po operacijos, kitai grupei buvo skirtas placebo. Lornoksikamo grupejje sumažejo skausmas, pykinimas ir vėmimas (8). Kitame tyrime (9) buvo lyginami trys vaistai - lornoksikamas, acetaminofenas ir diklofenakas. İrodyta, kad visi vaistai veikia vienodai efektyviai, tačiau vartojama mažesnè dozė lornoksikamo, todèl pasitaiko mažiau šalutinių reiškinių. Moksliniame tyrime (1) įrodyta, kad $8 \mathrm{mg}$ lornoksikamo dozè efektyviai malšina skausmą 4 valandas ir savo efektyvumu atitinka $200 \mathrm{mg}$ ibuprofeno, taip pat šis vaistas yra efektyvesnis už $1000 \mathrm{mg}$ acetaminofeno. Atsižvelgdami i kitų autorių išvadas, pastebèjome, kad lornoksikamas sukelia mažiau šalutinių reiškinių ir, vieno tyrimo duomenimis, yra efektyvesnis už acetaminofeną, todèl pasirinkome lyginti acetaminofeno $1000 \mathrm{mg}$ i/v ir lornoksikamo $8 \mathrm{mg}$ i/v efektyvumo jëgas pooperaciniam skausmui malšinti.

Darbo tikslas: ịvertinti lornoksikamo analgezijos efektyvumo jëgą pooperaciniu laikotarpiu pacientams po radikalių prostatektomijų.

\section{Medžiaga ir tyrimo metodas}

I ši tyrimą buvo įtraukti 35 pacientai, gydyti 2015-2016 metais LSMUL KK Urologijos skyriuje, kuriems atlikta radikali prostatektomija. Kauno regioninis biomedicininių tyrimų etikos komitetas suteiké leidimą (BEC-MF-319) šiam tyrimui atlikti. Gavus raštišką paciento informuotą sutikimą dalyvauti tyrime, likus $30 \mathrm{~min}$. iki operacijos pabaigos atsitiktiniu būdu buvo sušvirkščiami intraveninio lornoksikamo 8 mg arba acetaminofeno 1000 mg. Kitos są- lygos pacientams nesiskyrė - taikyta bendrinè anestezija, prieš operaciją nevartoti analgetikai. Pilvo skausmas vertintas prieš operaciją, po operacijos praejus 3, 6, 12 ir 24 valandoms, naudojant skaitinę skausmo skalę. Demografiniai duomenys, operacijos pradžia ir pabaiga, skausmo subjektyvus vertinimas, šalutinès ligos, vartotas vaistas nuo skausmo prieš operaciją, papildomų vaistų vartojimas užrašomi apklausos metu ị specialiai šiam darbui sudarytą anketą ( 1 pav.). Pacientai atrinkti pagal šiuos reikalavimus: 1) atlikta radikali prostatektomija; 2) atlikta bendrinè anestezija; 3) I-III ASA klasės; 4) prieš operaciją nevartotas analgetikas; 5) sutiko dalyvauti tyrime. Atmetimo kriterijai: 1) anksčiau buvusios urologinès operacijos; 2) atlikta TAP (angl. transversus abdominis plane) blokada; 3) IV ASA klasé; 4) prieš operaciją vartoti analgetikai; 5) atsisakè dalyvauti tyrime. Duomenims analizuoti taikyti Wilcoxon ir Paired-samples T-test testai. Skirtumas buvo statistiškai reikšmingas, kai $p<0,05$.

\section{POOPERACINIO SKAUSMO VALDYMO LORNOKSIKAMU IR ACETAMINOFENU} PALYGINIMAS

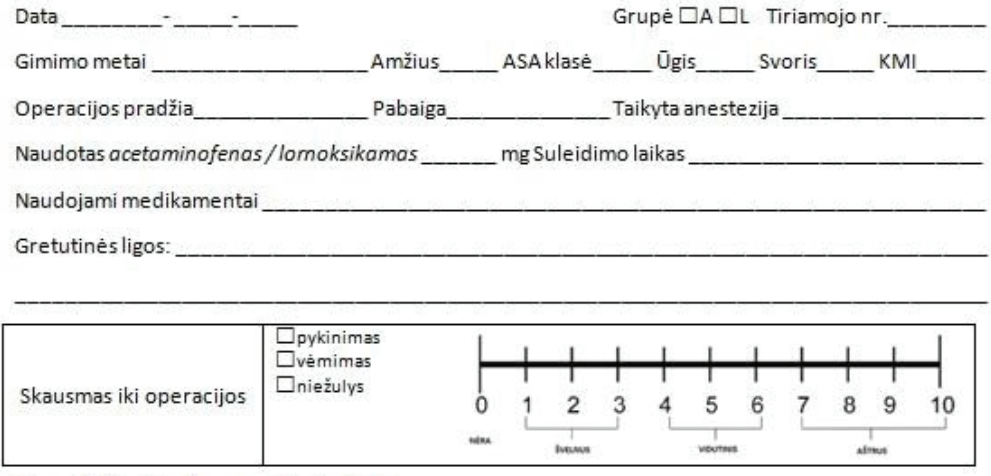

Kitos lokalizacijos skausmas $\square$ nèra $\square$ yra

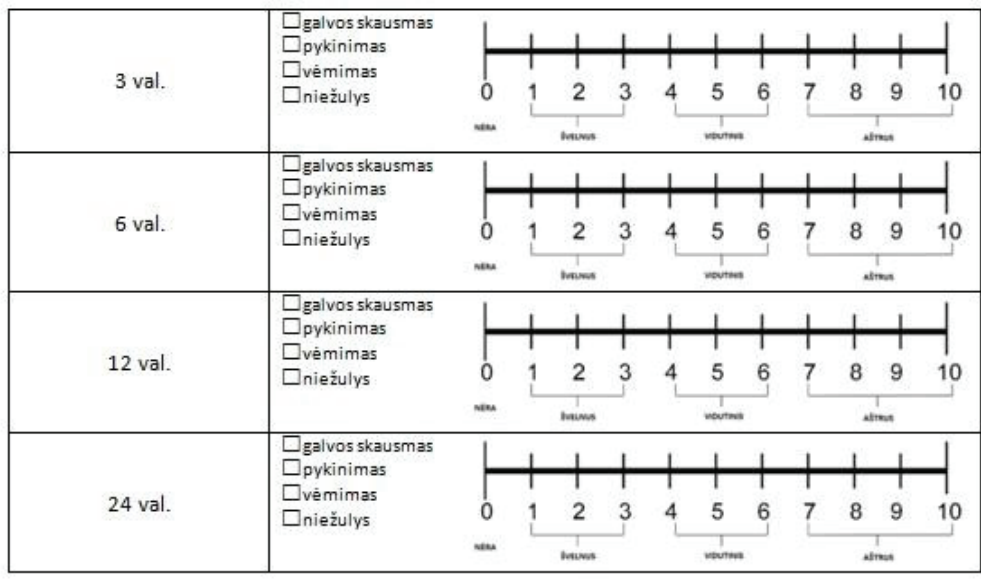

Ar skausmas trukdè užmigti? $\square$ taip $\square$ ne

Ar skausmas trukdè miegoti? $\square$ taip $\square$ ne

1 pav. Tyrimo anketa, naudota pacientu atrankai ir pooperaciniam skausmui vertinti 


\section{Rezultatai ir jų aptarimas}

Tyrime dalyvavo 35 pacientai, kuriems buvo atlikta radikali prostatektomija. I lornoksikamo (L) grupę buvo įtraukti 16, o i acetaminofeno (A) - 19 pacientų. Pacientų amžiaus vidurkis lornoksikamo grupejje buvo $62 \pm$ 5,45 metų, o acetaminofeno $-61 \pm 5,7$ metų $(p>0,05)$. $\mathrm{L}$ ir A grupèse pacientų kūno masès indeksas statistiškai reikšmingai nesiskyrè ( $p=0,959), 26,71 \mathrm{vs} 26,77 \mathrm{~kg} / \mathrm{m} 2$, atitinkamai. Statistiškai reikšmingo skirtumo tarp L ir A grupių tiriamujų, vertinant ASA klases, nebuvo $(\mathrm{p}>0,05)$.

Prieš operaciją pilvo skausmą pacientu grupėje, kurioje vartotas lornoksikamas, jaute 1 (6,25 proc.) pacientas. Po operacijos praejus 3 valandoms skausmo nejuto 3 $(18,75$ proc.) pacientai, 6 (37,5 proc.) jaute švelnų skausmą, 4 (25 proc.) - vidutinio stiprumo skausmą ir $3(18,75$ proc.) - skundèsi stipriu skausmu. Po operacijos praejus 6 valandoms skausmo nejuto 3 (18,75 proc.) pacientai, 7 $(43,75$ proc.) jautė švelnų skausmą, 6 (37,5 proc.) - vidutinio stiprumo skausmą. Po operacijos praejus 12 valandu skausmo nejuto 4 (25 proc.) pacientai, 8 (50 proc.) jautè švelnų skausmą, 2 (12,5 proc.) - vidutinio stiprumo skausmą ir 2 (12,5 proc.) skundèsi stipriu skausmu. Po operacijos praejjus 24 valandoms skausmo nejuto $3(18,75$ proc.) pacientai, 10 (62,5 proc.) jautè švelnų skausmą, 3 $(18,75$ proc. $)$ - vidutinio stiprumo skausmą. Duomenys pateikti 2 paveiksle.

Prieš operaciją pacientu grupejje, kurioje vartotas acetaminofenas, 1 (5,26 proc.) pacientas jautė rankos skausmą. Po operacijos praejjus 3 valandoms skausmo nejuto 1 (5,26 proc.) pacientas, 5 (26,32 proc.) jautè švelnų skausmą, 9 (47,37 proc.) - vidutinio stiprumo skausmą ir 3 ( 15,79 proc.) - skundèsi stipriu skausmu. Po operacijos praejjus 6 valandoms skausmo nejuto 2 (10,53 proc.) pacientai, 9 (47,37 proc.) jautè švelnų skausmą, 7 (36,84 proc.) - vidutinio stiprumo skausmą ir 1 (5,26 proc.) skundèsi stipriu skausmu. Po operacijos praejus 12 valandų skausmo nejuto 1 (5,26 proc.) pacientas, 11 (57,9 proc.) jautė švelnų skausmą, 6 (31,58 proc.) - vidutinio stiprumo skausmą ir $1(5,26$ proc. $)$ - skundèsi stipriu skausmu. Po operacijos praejjus 24 valandoms skausmo nejuto $4(21,05$ proc.) pacientai, 14 (73,69 proc.) jautė švelnų skausmą, 1 (5,26 proc.) - vidutinio stiprumo skausmą. Duomenys pateikti 3 paveiksle.

Palyginus skausmo stiprumą tarp L ir A grupių pacientų, praejus 3, 6, 12 ir 24 valandoms po operacijos, statistiškai reikšmingų skirtumų nebuvo $(\mathrm{p}=0,329 ; 0,917 ; 0,4$; 0,903, atitinkamai).

Mūsų tyrimo duomenimis, L grupejje 1 (6,25 proc.), o A grupejje 3 (15,79 proc.) pacientams buvo sunku užmigti dèl skausmo $(\mathrm{p}=0,1)$. Dèl skausmo nakties metu $\mathrm{L}$ grupejje prabudo 3 (18,75 proc.), o A grupeje 8 (42,11 proc.) pacientai $(\mathrm{p}=0,1)$.

Tyrimo metu né vienam pacientui nebuvo nepageidaujamų reiškinių, praejjus 3, 6, 12 ir 24 valandoms po operacijos.

Efektyvus nuskausminimas yra labai svarbus pooperacinès priežiūros komponentas. Operacijos pabaigoje suleidžiami intraveniniai analgetikai pooperacinio skausmo valdymui ir su skausmu susijusioms komplikacijoms (tachikardija, hipertenzija, miokardo išemija, alveolių venti-

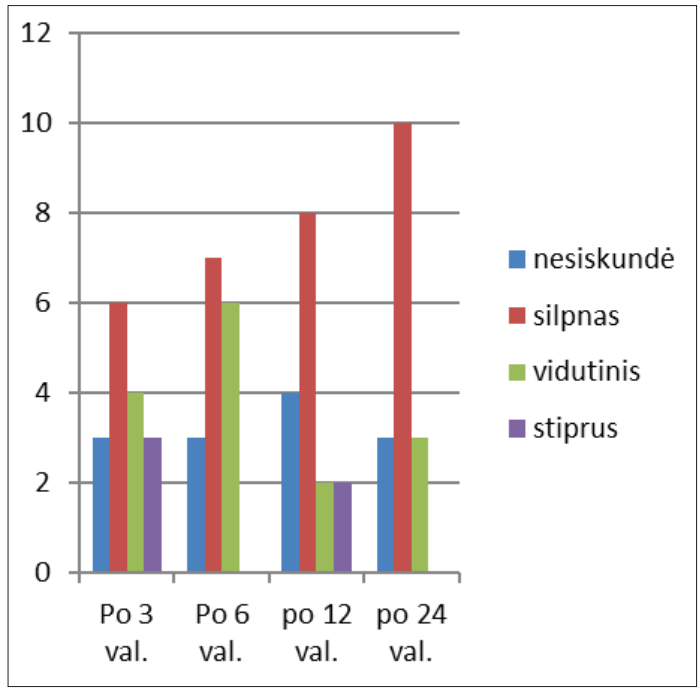

2 pav. Lornoksikamo efektyvumas pagal skaitinę skausmo skalę

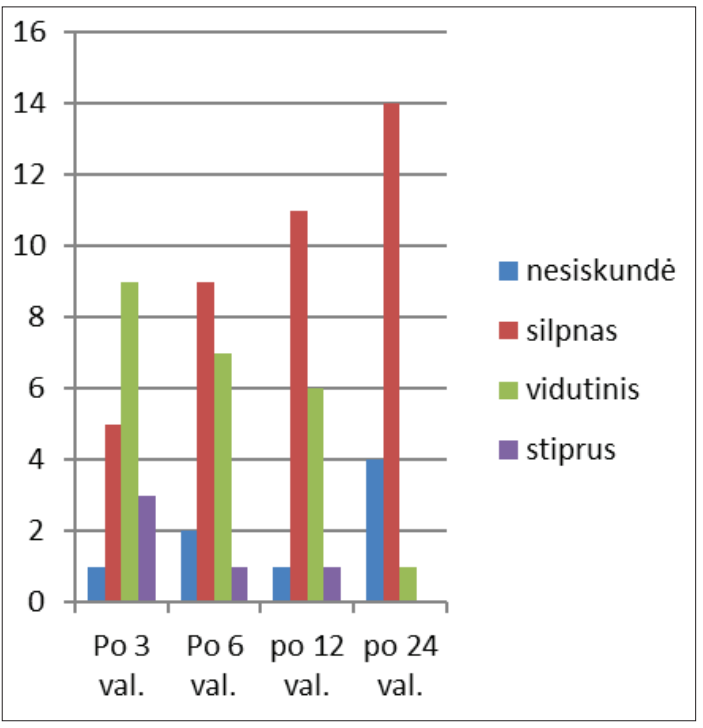

3 pav. Paracetamolio efektyvumas pagal skaitinę skausmo skalę 
liacijos sumažejimas, prastas žaizdų gijimas) išvengti.

Lornoksikamas priklauso NVNU grupei, skirtas malšinti silpną ir vidutinio stiprumo skausmą. Pooperacinio skausmo valdymas nėra apibrèžtas lornoksikamo terapinèse indikacijose (10). Remiantis atliktais tyrimais (1, 6-9), sunku teisingai ịvertinti gautus duomenis apie lornoksikamo pranašumą prieš kitus analgetikus dèl skirtingų tyrimų metodikų. Tačiau keliuose tyrimuose lornoksikamas veikè taip pat efektyviai kaip petidinas (11), morfinas $(12)$ ir tramadolis $(13,14)$. Taip pat lornoksikamas yra gerai toleruojamas pooperaciniu periodu, nes dèl trumpo pusinès eliminacijos laiko (apie 4 valandas) retai sukèlé nepageidaujamų reakcijų (11-14).

Intraveninis paracetamolis yra neopioidinis, greitai veikiantis, efektyvus ir vienas iš saugiausių analgetiku pooperaciniam skausmui mažinti $(15,16)$. Acetaminofenas yra rekomenduojamas Europos regioninès anestezijos ir skausmo terapijos asociacijos (ESRA) pooperaciniam skausmui valdyti (17). Barden ir bendraautorių (18) atlikta metaanalizè nurodo, kad vienkartiné paracetamolio dozè yra efektyvi vidutinio ir stipraus pooperacinio skausmo malšinimui.

Korkmaz Dilmen ir bendraautoriai (19) lygino paracetamoli, metamizoli ir lornoksikamą pooperaciniam skausmui valdyti po stuburo išvaržų operacijų. Jų rezultatai parodè, kad paracetamolis ir metamizolis buvo efektyvesni už lornoksikamą skausmui malšinti. Mūsų tyrimo duomenimis, tiek acetaminofenas, tiek lornoksikamas buvo efektyvus, mažinant pooperacini skausmą po radikalių prostatektomijų. Mowafi su bendraautoriais (20) nustaté, kad lornoksikamas buvo efektyvesnis už paracetamoli po apatinès pilvo srities operacijų kaip papildomas analgetikas. Mūsų tyrime per pirmąsias šešias valandas po radikalios prostatektomijos lornoksikamas veikè efektyviau nei acetaminofenas. Kitame tyrime (21) buvo lyginta vietiné infiltraciné anestezija levobupivakainu, intraveninis paracetamolis ir intraveninis lornoksikamas. Rezultatai parodè, kad paracetamolis ir lornoksikamas buvo efektyvesni už infiltracinę anesteziją ir tarpusavy jų veikimas nesiskyrè. Mūsų atliktame tyrime lornoksikamas veikè ilgiau nei paracetamolis, tačiau pagal skaitinę skausmo skalę rezultatai beveik nesiskyrè. Hein ir bendraautoriai (22) lygino paracetamolio ir lornoksikamo efektyvumą po gimdos abrazijų. Rezultatai parodè, jog lornoksikamas buvo statistiškai reikšmingai veiksmingesnis nei acetaminofenas. Mūsų tyrimo duomenimis, L grupèje po trijų valandų daugiausia pacientų skundèsi silpnu, o A grupèje - vidutinio stiprumo skausmu, todèl galime manyti, kad lornoksikamas buvo efektyvesnis už paracetamolį. Arslan ir bendraautoriai (8) vertino pooperacinị skausmą po tiroidektomijų. Vienoje grupejje buvo vartota i/v $8 \mathrm{mg}$ lornoksikamo operacijos pabaigoje bei dvi dozès po $8 \mathrm{mg}$ i/v kas 12 valandu po operacijos, kitai grupei buvo skirtas placebo. Lornoksikamo grupėje sumažèjo skausmas, pykinimas ir vėmimas (8). Mūsų tyrime nei vienam pacientui nepasireiškè nei vienas šalutinis poveikis (galvos skausmas, pykinimas, vėmimas, niežulys ir kt.).

Mūsų gauti duomenys dar kartą patvirtina, kad lornoksikamas ir paracetamolis turi panašią efektyvumo jègą. Tačiau lornoksikamo analgezinis poveikis buvo ilgesnis po radikalių prostatektomijų ir truko apie šešias valandas. Mūsų tyrimo duomenimis, gydant lornoksikamu, per pirmąsias šešias valandas po operacijos mažiau pacientų skundèsi vidutinio stiprumo ar stipriu skausmu nei acetaminofeno grupejje. Siekiamybè pooperaciniu periodu yra adekvatus skausmo numalšinimas, vartojant mažiausias optimalias vaisto dozes.

\section{Išvados}

Intraveninis lornoksikamas ir acetaminofenas efektyviai malšina skausmą po radikalių protatektomijų. Lornoksikamas $\mathrm{i} / \mathrm{v}$ yra toks pat efektyvus kaip paracetamolis $\mathrm{i} / \mathrm{v}$ pacientams po radikalių prostatektomijų. Intraveninis lornoksikamas ir paracetamolis yra tinkami vartoti vidutinio stiprumo ir stipriam skausmui malšinti ankstyvuoju pooperaciniu laikotarpiu.

\section{Literatūra}

1. Hall PE, Derry S, Moore RA, McQuay HJ. Single dose oral lornoxicam for acute postoperative pain in adults (Review). Cochrane Database Syst Rev 2009; (4).

2. Ragaišis D., Sveikata A., Gumbrevičius G., Sveikatienė R., Milašius A. Nesteroidinių vaistų nuo uždegimo farmakologinių savybių apžvalga. KMU Teorinès ir klinikinès farmakologijos katedra. Lietuvos bendrosios praktikos gydytojas, 2010; 14(1):71-75. Prieiga:http://www.vitaelitera.lt/ ojs/index.php/bedrosios-praktikos-gydytojas/article/viewArticle/587(2016-04-13)

3. Graham GG, Scott KF. Mechanism of action of paracetamol. Am J Ther 2005;12(1):46-55.

https://doi.org/10.1097/00045391-200501000-00008

4. Ducharme J. Acute pain and pain control: State of the art. Annals of Emergency Medicine 2000; 35(6): 592-603. https://doi.org/10.1016/S0196-0644(00)70033-3

5. Vadivelu N, Mitra S, Narayan D. Recent advances in postoperative pain management. Yale J Biol Med 2010; 83:11-25.

6. Mentes O, Bagei M. Postoperative pain management after inguinal hernia repair: lornoxicam versus tramadol. Hernia 2009; 13:427-430.

https://doi.org/10.1007/s10029-009-0486-1

7. Nørholt SE, Sindet-Pedersen S, Larsen U, Bang U, Ingerslev J, Nielsen O, Hansen HJ, Ersbøll AK. Pain control after dental surgery: a double-blind, randomised trial of lornoxicam versus 
morphine. Pain 1996; 67:335-343.

https://doi.org/10.1016/0304-3959(96)03126-0

8. Arslan M, Tuncer B, Babacan A, Taneri F, Karadenizli Y, Onuk E. Postoperative analgesic effects of lornoxicam after thyroidectomy: a placebo controlled randomized study. Agri 2006; 182:27-33.

9. TuzunerOncul AM, Yazicioglu D, Alanoglu Z, Demiralp S, Ozturk A, Ucok C. Postoperative analgesia in impacted third molar surgery: the role of preoperative diclofenac sodium, paracetamol and lornoxicam. Med PrincPract 2011; 20:470-6. https://doi.org/10.1159/000327658

10. Valstybinè vaistų kontrolès tarnyba. Lornoksikamas, $8 \mathrm{mg}$ injekcinis tirpalas. Prieiga: http://extranet.vvkt.lt/paieska/ (2016-04-13)

11. Balfour JA, Fitton A, Barradell LB: Lornoxicam. A review of its pharmacology and therapeutic potential in the management of painful and inflammatory conditions. Drugs 1996; 51:639-57. https://doi.org/10.2165/00003495-199651040-00008

12. Rosenow DE, Albrechtsen M, Stolke D: A comparison of patient-controlled analgesia with lornoxicam versus morphine in patients undergoing lumbar disk surgery. AnesthAnalg 1998;86:1045-50. https://doi.org/10.1213/00000539-199805000-00026

13. Ilias W, Jansen M: Pain control after hysterectomy: an observer-blind, randomised trial of lornoxicam versus tramadol. $\mathrm{Br}$ J ClinPract 1996;50:197-202.

14. Staunstrup H, Ovesen J, Larsen UT, Elbaek K, Larsen U, Krøner $\mathrm{K}$ : Efficacy and tolerability of lornoxicam versus tramadol in postoperative pain. J ClinPharmacol 1999; 39:834-41. https://doi.org/10.1177/00912709922008362

15. Sinatra RS, Jahr JS, Reynolds LW, Viscusi ER, Groudine SB, Payen-Champenois C. Efficacy and safety of single and repeated administration of 1 gram intravenous acetaminophen injection (paracetamol) for pain management after major orthopedic surgery. Anesthesiology 2005; 102(4):822-31. https://doi.org/10.1097/00000542-200504000-00019

16. Bertolini A, Ferrari A, Ottani A, Guerzoni S, Tacchi R, Sheila L. Paracetamol: new vistas of an old drug. CNS Drugs Reviews $2006 ; 12$.

17. European Society of Regional Anaesthesia and Pain Therapy. Postoperative pain management - good clinical practice. 2011; Available online: http://www.nmu.edu.ua/files/e13/postoperative_pain_management.pdf(2016-04-13)

18. Barden J, Edwards J, Moore A, McQuay H. Single dose oral paracetamol (acetaminophen) for postoperative pain. Cochrane Database Syst Rev 2004; (1).

19. KorkmazDilmen O, Tunali Y, Cakmakkaya OS, Yentur E, Tutuncu AC, Tureci E, Bahar M.Efficacy of intravenous paracetamol, metamizol and lornoxicam on postoperative pain and morphine consumption after lumbar disc surgery.Eur $\mathrm{J}$ Anaesthesiol 2010; 27(5):428-32. https://doi.org/10.1097/EJA.0b013e32833731a4

20. Mowafi HA, Elmakarim EA, Ismail S, Al-Mahdy M, El-Saflan AE, Elsaid AS. Intravenous lornoxicam is more effective than paracetamol as a supplemental analgesic after lower abdominal surgery: a randomized controlled trial. World J Surg 2012; 36(9):2039-44.

https://doi.org/10.1007/s00268-012-1649-2

21. Tuncel A, Balci M, Postaci A, Aslan Y, Atan A. Comparıson of different postoperative pain managements in patients submitted to transperitoneal laparoscopic renal and adrenal surgery. IntBraz J Urol 2015; 41(4):669-75.

https://doi.org/10.1590/S1677-5538.IBJU.2013.0238

22. Hein A, Norlander C, Blom L, Jakobsson J. Is pain prophylaxis in minor gynaecological surgery of clinical value? A doubleblind placebo controlled study of paracetamol $1 \mathrm{~g}$ versus lornoxicam 8 mg given orally. Ambul Surg 2001; 9(2):91-94. https:/doi.org/10.1016/S0966-6532(01)00078-6

\section{LORNOXICAM AND ACETAMINOPHEN COMPARISON IN POSTOPERATIVE PAIN MANAGEMENT}

\section{U. Lindžiūtè, E. Zlatkutė, T. Urbonas, T. Bukauskas, D. Simonaitis,}

A. Macas

Key words: postoperative pain; non-steroidal anti-inflammatory drugs; intravenous lornoxicam; intravenous acetaminophen.

Summary

Introduction: Non-steroidal anti-inflammatory drugs (NSAIDs) are usually used to treat various severity and localization pain. Acceptable postoperative pain management should be acquired to avoid tachycardia, elevated blood pressure, myocardial ischemia, decreased alveolar ventilation, poor healing of wounds. This article puts acetaminophen and lornoxicam in comparison to determine which drug has greater efficacy in postoperative pain management.

The aim of the study was to evaluate lornoxicam's analgesic efficacy in postoperative pain management.

Methods: A total of 35 patients after radical prostatectomy were treated in LUHS Kaunas Clinics Urology department. Informed consent was obtained from all patients. Injection of intravenous analgesic drug was randomized and patients received 1000mg acetaminophen or $8 \mathrm{mg}$ lornoxicam during radical prostatectomy. Abdominal pain was measured 3, 6, 12 and 24 hours after every surgery.

Results: $1(6.25 \%)$ patient in lornoxicam (L) group had abdominal pain before surgery. In acetaminophen (A) group $1(5.26 \%)$ patient had forearm pain. Pain was measured after successful radical prostatectomies. In acetaminophen group, 3 hours after surgery, 9 (47.37\%) patients experienced average, 3 (15.79\%) severe abdominal pain. In lornoxicam group, 3 hours after surgery, 3 (18,75\%) patients experienced severe pain. There was no significant difference between A and L groups, after 3, 6, 12 and 24 hours $(p=0.329 ; p=0.917 ; p=0.4$; $\mathrm{p}=0.903$, respectively).

Conclusion: Both intravenous lornoxicam and paracetamol had similar efficacy in postoperative pain management following radical prostatectomies. Intravenous lornoxicam was as effective as intravenous acetaminophen following radical prostatectomies. Both intravenous lornoxicam and paracetamol are suitable to manage average and severe pain during early postoperative period.

Correspondence to: ugne.lindziute@gmail.com

Gauta 2017-03-08 